\title{
Prediction of Coating Properties of Thermally Sprayed WC-Co on Complex Geometries
}

\author{
Vasileios Katranidis $^{1} \cdot$ Spyros Kamnis $^{2} \cdot$ Sai Gu $^{1}$
}

Submitted: 31 May 2018/in revised form: 12 July 2018/Published online: 25 July 2018

(C) The Author(s) 2018

\begin{abstract}
This work outlines the development of an analytical software tool that enables the prediction of various coating properties on any given sprayable geometry. The prediction is achieved by analyzing the input computeraided design geometry and by correlating the resulting kinematic conditions with experimental measurements. The results of the developed tool have been validated experimentally using HVOF-sprayed WC-17Co coatings. Specifically, coating thickness, microhardness, WC vol.\% and specific sliding wear rate are examined and their values are predicted for the case of the external spray of a rotorlike model.
\end{abstract}

Keywords complex geometries $\cdot$ HVOF $\cdot$ spray angle . thermal spray $\cdot$ WC-Co $\cdot$ wear

\section{Introduction}

Thermal spray processes have shown applicability in a broad variety of coating applications (Ref 1). A range of metallurgical, ceramic or composite (hard metal) materials have been successfully sprayed providing environmental protection to the underlying part, or endowing desired surface properties to it. Yet, these processes are line-ofsight methods and as such they yield significant variance in the spray angle, spray distance and gun traverse speed,

Vasileios Katranidis

v.katranidis@surrey.ac.uk

1 Department of Chemical and Process Engineering, University of Surrey, Guildford GU2 7XH, UK

2 Monitor Coatings, 2 Elm Road, Tyne and Wear NE29 8SE, UK when the spray plume is traversed over a complex geometry, or equivalently, when a complex geometry is rotated in front of the plume. These are termed spray kinematic parameters and affect significantly the final coating's properties through their influence on the impinging particle's velocity (magnitude and direction), thermal history, temperature, mass and heat transfer to the coated surface (Ref 2). Certain widely used materials, such as WC-based hard metals, are particularly sensitive to excessive heating which may result from non-optimal spray distance owing to undesired dissolution and chemical reactions occurring in-flight (Ref 3, 4). For the reasons above, the established industrial applications of thermally sprayed coatings revolve around spraying plane surfaces via translation of the spray gun or axisymmetric components via rotation of the component in front of the spray equipment. Nevertheless, there is an increasingly pressing demand to coat more complex geometries and expand the scope of the thermal spray applications. Various industries such as the medical [coating of medical implants (Ref 5)], aerospace [turbine blades, airfoils, seals (Ref 1)], steel production [billet molds (Ref 6, 7)], off-shore oil drilling [rotors (Ref 6)] and many others are seeking an efficient and reliable way of applying thermal spray coatings on complex geometries. Considering the family of hard metal and wear-/corrosionresistant coatings, the need to spray more complex geometries is augmented by the recent regulations banning the use of hard-chrome plating coatings (Ref 8), owing to the detrimental environmental and health effects of hexavalent chrome.

To that aim, there have been attempts to thermally spray complex geometries by moving the spray gun along a complex path that is tailored to the sprayed geometry, intending to maintain the spray kinematic parameters constant during the spray process (Ref 9). Yet, this 
approach is costly in resources (sophisticated handling robots) and time and does not always pose a viable solution (Ref 10). Perhaps a better suited approach is to extensively examine the negative effects of non-optimal spray kinematic parameters on the coatings (Ref 10-16) and derive appropriate tolerances in their variability during the spray process, with respect to the requirements of the specific end application. The variability of the spray kinematic parameters is a function of the shape being sprayed, the relative position of the spray gun and the speed of rotation of the part (or equivalently of the translation of the spray gun over the surface, when a plane-type geometry is sprayed).

This work builds on the experimental results of previous studies that discuss the effects of the spray kinematic parameters on various HVOF-sprayed WC-17Co coating properties (Ref 17,18$)$ and presents an attempt to generalize the produced insights to valuable predictions on spraying arbitrarily complex geometries, internally or externally.

\section{Outline of the Kinematic Calculator}

The presented method has two prime objectives (Fig. 1): first, to analyze geometrically any given geometry into a data structure which will contain all the necessary information of the spray kinematic parameters associated with the geometry itself and secondly, to process the input experimental data so that a prediction, with respect to the calculated kinematic parameters, can be made. Such predictions are enabled only after the evaluation of the interplays between the spray kinematic parameters, since the manner in which they vary is coupled with the shape being sprayed and the relative position of the spray gun in space and, in that sense, unique to each case.

Although the method of the kinematic calculator can be generalized to model any coating material or thermal spray method, in this work, the application of WC-17Co with HVOF is examined due to the availability of experimental results from previous work (Ref 17,18$)$. It was shown that there is significant interplay between the spray distance and spray angle in determining the coating properties since both determine the impingement conditions of the particles. On the other hand, the gun traverse speed does not influence significantly the impingement conditions of the particles and thus its effect can be decoupled from the effects of spray angle and spray distance. Specifically, the gun traverse speed can influence certain aspects of the final coating via mechanisms that occur post-impingement and are governed by the heat and mass transfer from the thermal spray jet (Ref 18).

Considering the above, the experimental values for various coating properties which correspond to certain spray kinematic parameters are used to calculate their combined influence in a space (spray distance $\times$ spray angle $\times$ gun traverse speed) of possible combinations. The limits of the prediction space are dictated by the extreme values of the input experimental results. In the case study presented here, the experimental results from previous work (Ref 17, 18) were used as input for constructing the prediction space for the coating thickness, WC vol.\% and microhardness. Additionally, the sliding wear resistance was included in the study herein, though detailed analysis and discussion of the tribology of the coatings will be presented in a future publication. The exact kinematic conditions of the results that were used to construct the prediction space are given in Table 1 .

In the following sections, the essential functions of the algorithm will be discussed along with the case study of the external spray of a rotor-like geometry, shown in Fig. 3. This specific geometry is selected due to (1) its complexity and similarity to existing $\mathrm{WC}-\mathrm{Co}$ thermal spray
Fig. 1 Basic functionalities of the kinematic calculator

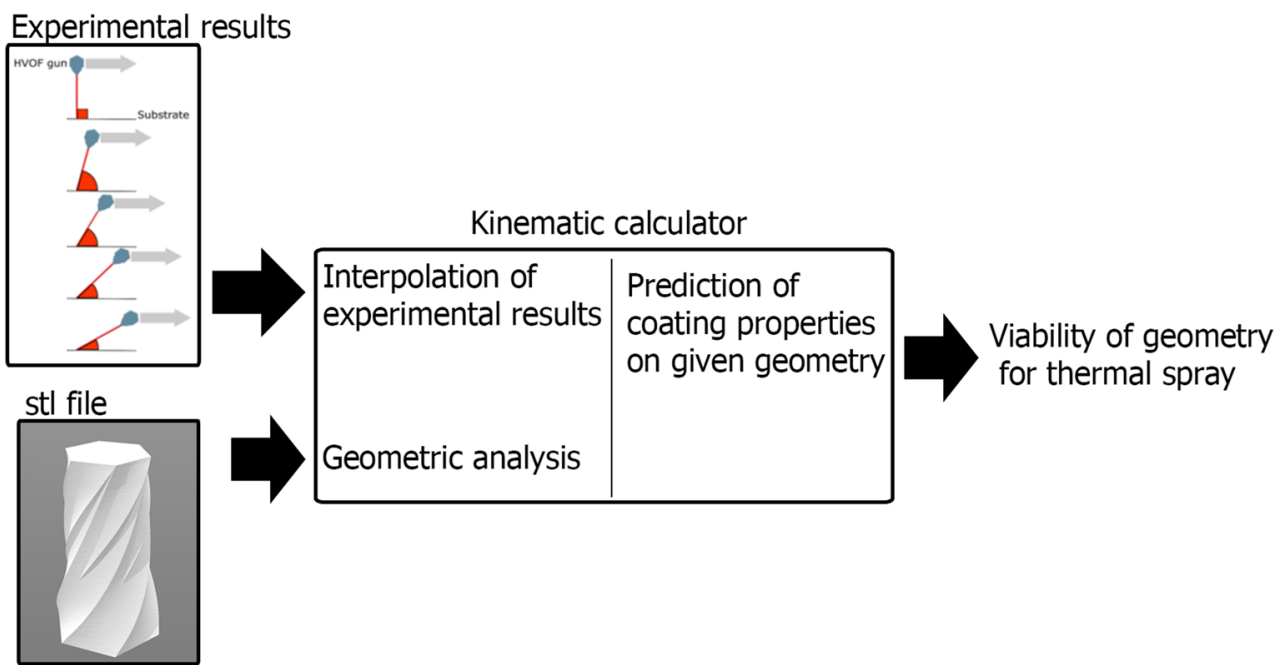


Table 1 Experimental results used as input for constructing the prediction space (Ref 17,18 )

\begin{tabular}{lccccc}
\hline Spray angle & $90^{\circ}$ & $75^{\circ}$ & $60^{\circ}$ & $45^{\circ}$ & $30^{\circ}$ \\
\hline SoD $120 \mathrm{~mm}$ & $\bullet$ & $\bullet$ & $\bullet$ & $\bullet$ & $\bullet$ \\
SoD $138 \mathrm{~mm}$ & $\bullet$ & $\bullet$ & $\bullet$ & $\bullet$ & $\bullet$ \\
SoD $170 \mathrm{~mm}$ & $\bullet$ & $\bullet$ & $\bullet$ & $\bullet$ & $\bullet$ \\
SoD $240 \mathrm{~mm}$ & $\bullet$ & $\bullet$ & $\bullet$ & $\bullet$ & $\bullet$ \\
\hline Traverse speed & & $502, \mathrm{~mm} /$ & 670, & $2010, \mathrm{~mm} /$ \\
& & $\mathrm{s}$ & $\mathrm{mm} / \mathrm{s}$ & $\mathrm{s}$ \\
\hline SoD $120 \mathrm{~mm} /$ spray angle & $\bullet$ & & \multicolumn{2}{c}{$\bullet$} \\
$90^{\circ}$ & & &
\end{tabular}

The bullet points represent individual experiments that were executed at the respective conditions

applications and (2) the inclusion of the resulting spray kinematic conditions to the available prediction space (Table 1).

Concerning the validation of the presented method (Fig. 1), predictions made for a simple case of a rotating plane substrate around the spray gun are compared with experimental results of the same configuration (Fig. 2). This configuration [further discussed in (Ref 17)] can be regarded as a simple case where the spray kinematic parameters vary simultaneously and thus can be a used as a test for the predictive ability of the discussed method. The choice of the dimensions and rotation speed of the modeled validation geometry was made to match the respective of the experiment that was used for the validation.

\section{Initialization}

The input geometry format is in standard tessellation language (STL), one of the most standard types of files used in the additive manufacturing and computer-aided engineering (CAE) fields. The geometry in an STL file is described as a triangulated, watertight surface defining the boundaries of the model. Essentially, an STL file is a list of the normal vectors and vertices of each constitutive triangle of the model. Normally, an STL file does not contain inherent information on the scale of the geometry (vertices have no units). In the case of this study, the dimensions of the part (Table 2) were chosen to approximate typical real-world scenario. Subsequently, certain user-defined parameters which are necessary for the calculation of the kinematic parameters are entered (Table 2). At this point, it should be noted that a constant spray pass offset was assumed in the presented method. Considering the changes in the shape and size of the spray footprint which are caused by the varying spray angle and spray distance, a constant spray pass offset yields varying spray pass overlap in regions which are sprayed at different spray angles and distances.

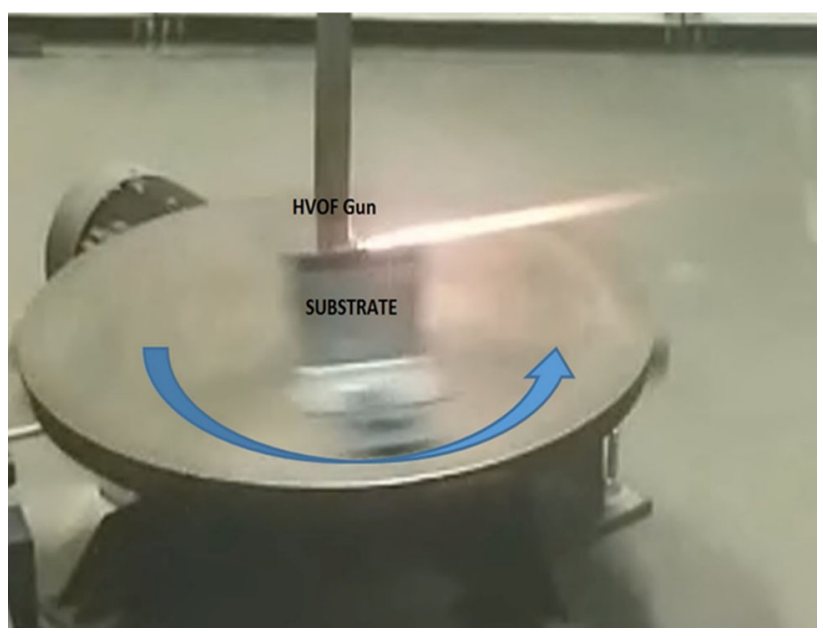

Fig. 2 Validation experiment: spraying a rotating plane around the fixed spray gun (Ref 17)

In our approach, this is considered a consequence of the geometrical complexity of the sprayed part and is included in the calculation and validation of the results. Future work will focus in the analysis and optimization of this aspect.

The spray footprint dimensions at specified conditions (i.e., at $120 \mathrm{~mm}$ of spray distance and $90^{\circ}$ of spray angle), pass overlap factor (10\% in this work) and the dimensions of the geometry are used to calculate the number and position ( $z$-axis coordinate) of the sprayed sections which need to be sprayed in order to coat the analyzed geometry. The next step is to calculate the center of mass of the geometry, through which the rotation axis is assumed to be passing. Subsequently, the geometry is recentered around the center of mass point and the rotation axis is created with a direction normal to the XY plane (Fig. 3).

For each calculated $\mathrm{z}$ position of the needed spray passes, a horizontal plane (with the same z-coordinate) is constructed. Using the function "intersect plane mesh" from the "geom3d" MATLAB toolbox (Ref 19), the coordinates of the intersections between the triangulated geometry and each of the constructed planes are calculated. This yields all the necessary points needed to acquire the 3-D polygons that correspond to each spray pass on the examined geometry. These closed polygons will be referred to as sprayed sections in this work. Considering the dimensions of the analyzed geometry and spray footprint as well as the overlap factor in Table 2, the rotor-like geometry is expressed by 140 sprayed sections, which are presented as vertically arranged polygons in Fig. 4. In the case that the geometry is hollow and open (i.e., internal spray is possible), two sets of sprayed sections are calculated (one for the external and one for the internal faces of the examined geometry) and the option of modeling external or internal spray is given. However, considering the rotor-like geometry that is studied herein, only external 
Table 2 User-defined parameters needed for initialization

\begin{tabular}{ll}
\hline User input & Values for the present case study \\
\hline STL file & "Rotor-like geometry" \\
Dimensions, $\mathrm{mm} \times \mathrm{mm} \times \mathrm{mm}$ & $388 \times 388 \times 630$ \\
Spray footprint at $90^{\circ}, 120 \mathrm{~mm}$ of SoD, $\mathrm{mm}$ & 5 \\
Rotation speed, rpm & 40 \\
Rotation axis-spray gun distance, $\mathrm{mm}$ & 320 \\
\hline
\end{tabular}

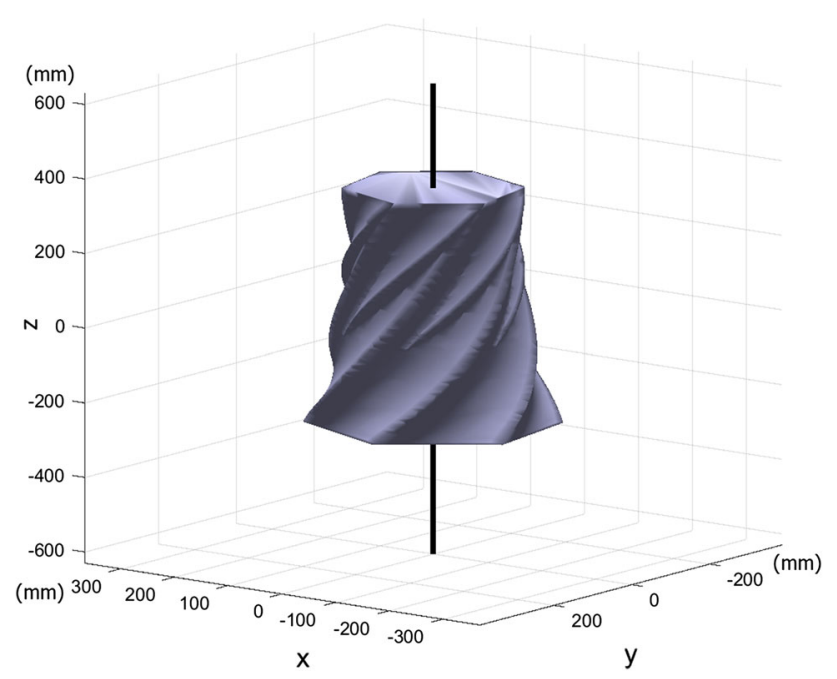

Fig. 3 Rotor-like geometry and the vertical rotation axis passing through the center of mass

spray is possible since the model is solid. In both cases (internal and external sprays), the position of the spray gun is defined relative to the rotation axis. In this work (external spray), the spray gun is assumed to be fixed at $320 \mathrm{~mm}$ from the rotation axis, with one degree of freedom, along the direction of the rotation axis.

Subsequently, each pass is discretized to the same number of nodes, yielding an ordered mesh spanning over the sprayed surface. The number of nodes for each sprayed cross section can be chosen by the user. In Fig. 5, such a mesh is created on the boundary surface of the analyzed model. The discretization method is based on the mapping of the intersection points between each sprayed section and $q$ equiangular, radial lines, passing through the rotation axis for each pass. In the case of this work, $q=180$ yielding 360 intersection points (nodes) on each sprayed section (each line intersects the closed polygon two times). Each discretized sprayed section appears in different colour in Fig. 5. This method closely imitates the line-of-sight nature of thermal spray and serves an additional purpose of indicating the sprayability of each of the sprayed section, and as a result, the sprayability of the geometry as a whole. In detail, if more than $2 q$ intersections are found in a sprayed section, it means that there is shadowing somewhere during part rotation and, respectively, less than
$2 n$ intersection points indicate an open polygon (i.e., an angular region during part rotation where the spray plume does not impinge on the sprayed part).

\section{Kinematic Calculations}

The construction of the ordered mesh from the initial STL file enables the calculation of the spray kinematic parameters for each of the nodes, for all sprayed sections. Considering the coordinates of the nodes, the rotation axis and the spray gun at each sprayed section, the calculation of the spray distance (SOD) for each node of each sprayed section is enabled. The scatter plot in Fig. 6 demonstrates the development of spray distance during one full rotation of the rotor-like model at the 3rd sprayed section from bottom (as shown in Fig. 5a). The 3rd sprayed section is chosen for demonstration purposes because it has low geometrical complexity (simple hexagon) which enables the easy visual correlation between the kinematic results and the geometry. In the examined geometry, the individual analysis of each sprayed section is necessary since they are unique in terms of coordinates. Considering the position of the spray gun $(320 \mathrm{~mm}$ off the rotation axis), the minimum spray distance occurs at the corners of the hexagonal sprayed section (Fig. 5a) and the maximum at the midpoints of each side, as it is sprayed externally. The six minima which are shown in Fig. 6 correspond to each of the six corners of the 3rd sprayed section.

For the calculation of the impact angle and gun traverse speed, the local neighborhood of each node must be considered. For the purpose of introducing the necessary elements that enable the calculation of impact angle and gun traverse speed, Fig. 7 illustrates a simple case of a plane mesh. In Fig. 7, every pair of adjacent nodes along the same sprayed section defines a vector $l$ and, respectively, the pairs of corresponding nodes at adjacent sprayed sections define the vector $k$ (Fig. 7). Iteratively, for each node, the vectors $k$ and $l$ define the local sprayed plane. In turn, the calculation of the impact angle is expressed as the complementary angle to the angle $\theta$ in Fig. 7, which is the angle between the vector normal to the local sprayed plane (denoted as $m$ in Fig. 7) and the vector of the spray plume. In light of the definition of the impact angle, it is bounded to the range of $0^{\circ}-90^{\circ}$. 

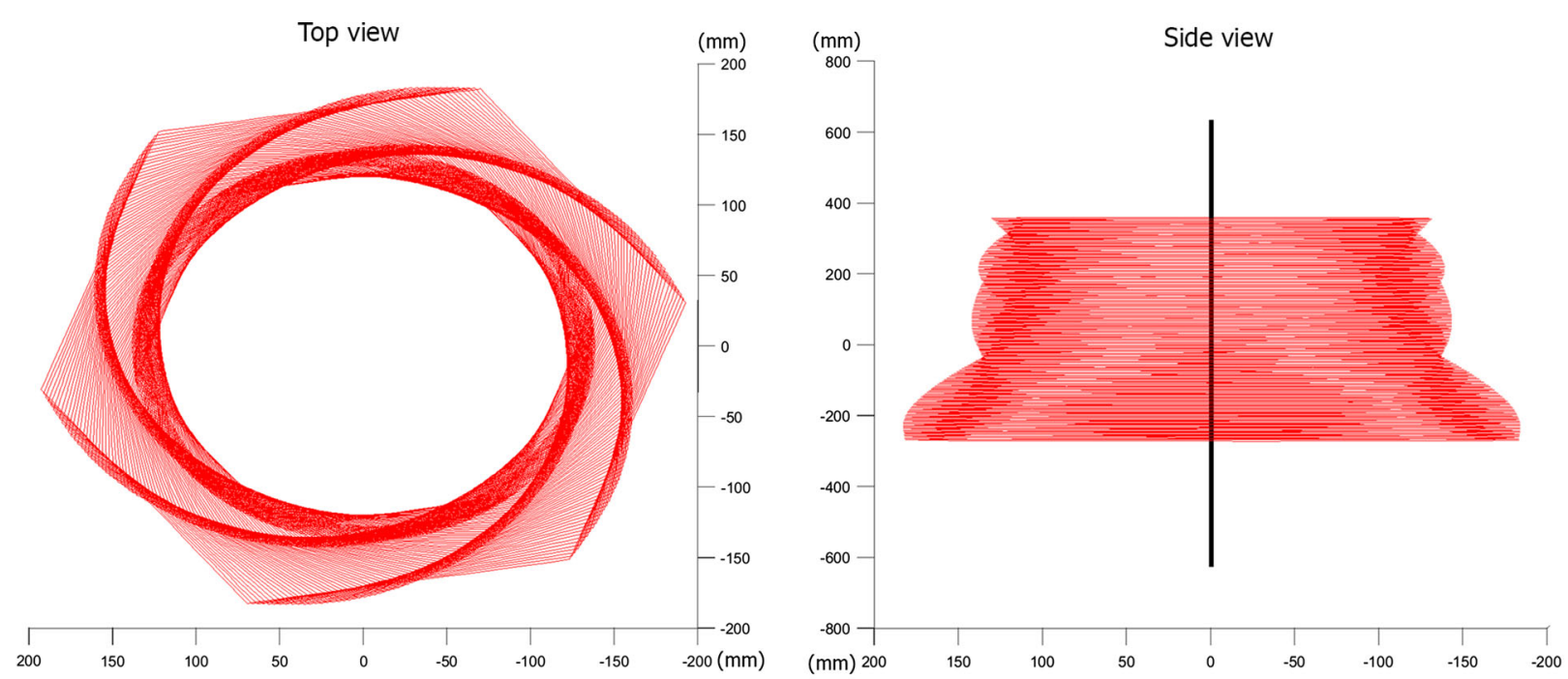

(a)

(b)

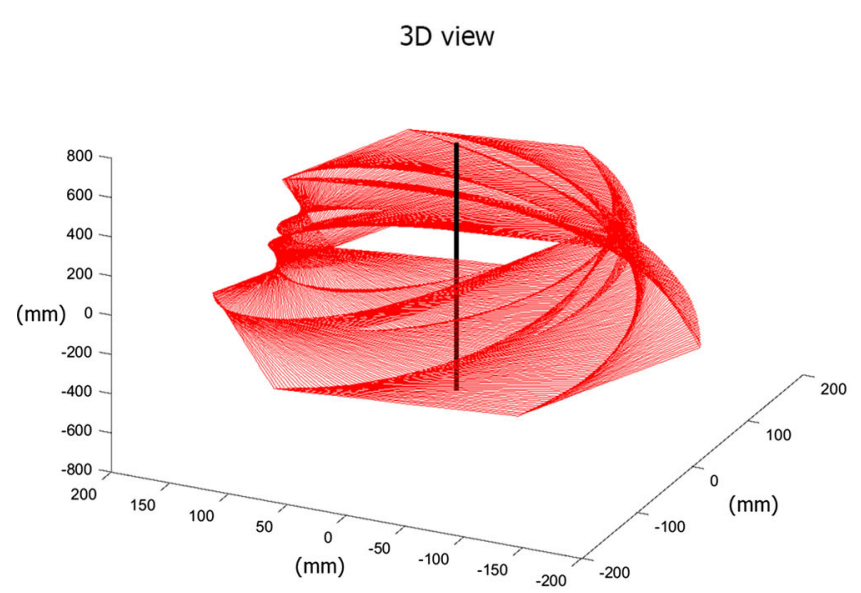

(c)

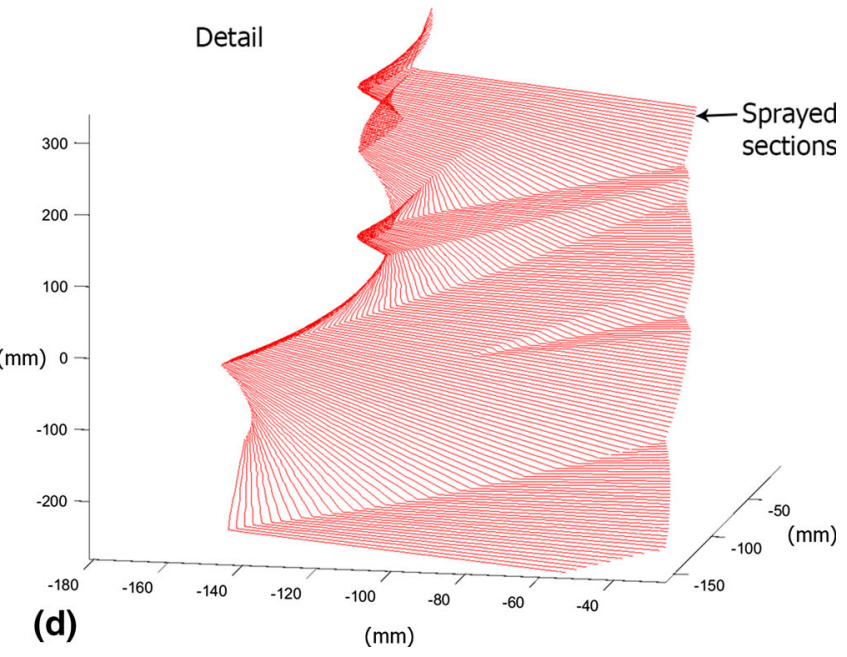

Fig. 4 Plot of the sprayed sections (a) top view, (b) side view, (c) 3D view, (d) detailed view
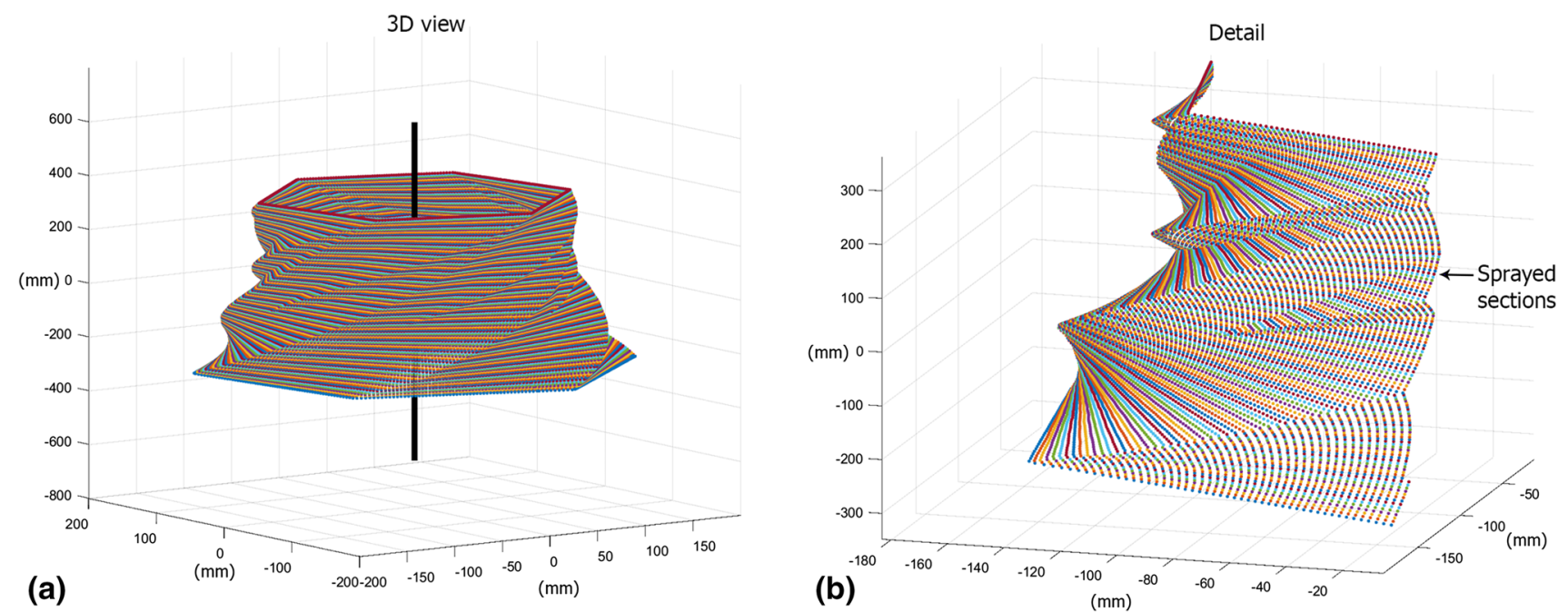

Fig. 5 Discretization of the sprayed sections (a) full view, (b) detailed view 


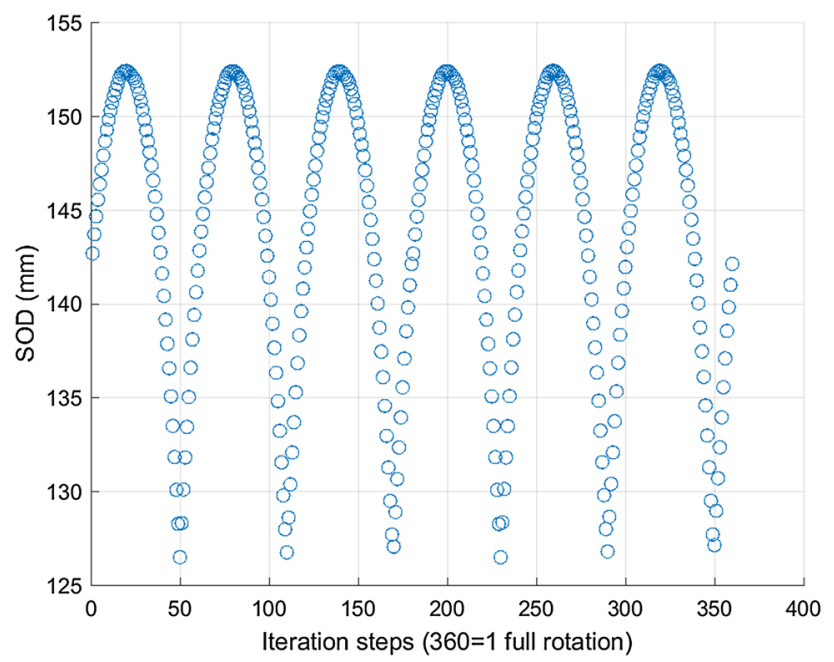

Fig. 6 Spray distance profile of the 3rd sprayed section during one full rotation of the part (external spray)

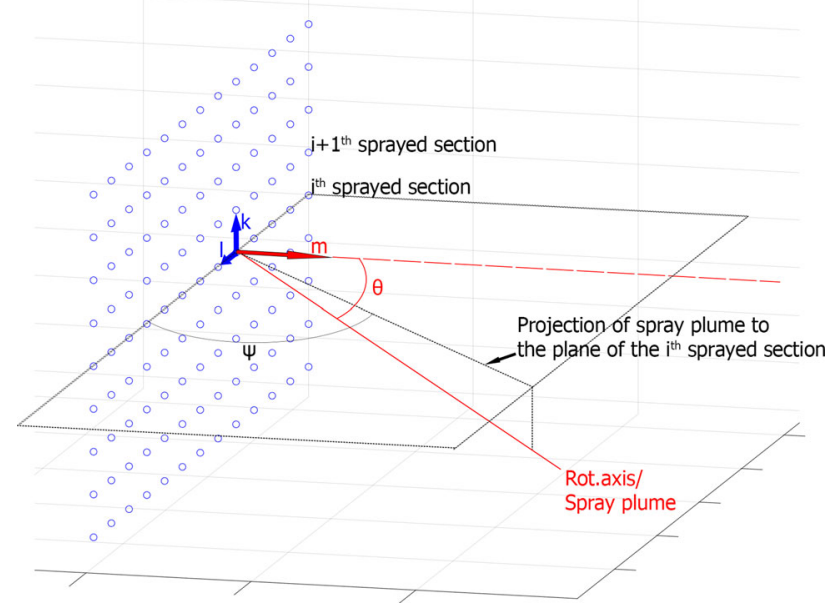

Fig. 7 Illustration of a simple case of a plane mesh. The vectors and angles which enable the calculation of the impact angle, azimuth angle and gun traverse speed are depicted

The scatter plot in Fig. 8 presents the behavior of the impact angle during one full rotation of the 3rd sprayed section of the studied model. The apparent range of impact angles is from $40^{\circ}$ to $85^{\circ}$. As expected by considering the shape of the 3rd sprayed section, the maximum impact angle coincides with the maximum SOD (Fig. 6), which marks the midpoints of the hexagonal cross section.

For every pair of adjacent nodes in a sprayed section, a quantity $W$ is defined, which is equal to the minimum distance between any two points lying on the lines defined by (1) the vector $l$ (Fig. 7 and 9) and (2) the rotation axis. The quantity $\mathrm{W}$ is illustrated in detail in Fig. 9, assuming two adjacent nodes in a given sprayed section (node1, node2 in Fig. 9); Q is the point on the line defined by vector $l$ from which the normal intersects the rotation axis, giving the minimum distance between them, which is

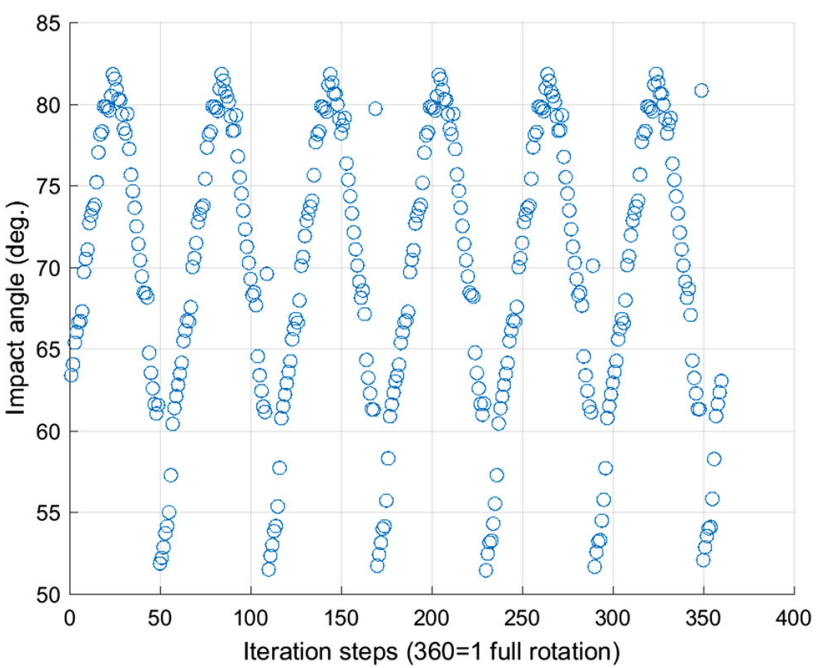

Fig. 8 Impact angle profile of the 3rd sprayed section during one full rotation of the part (external spray)

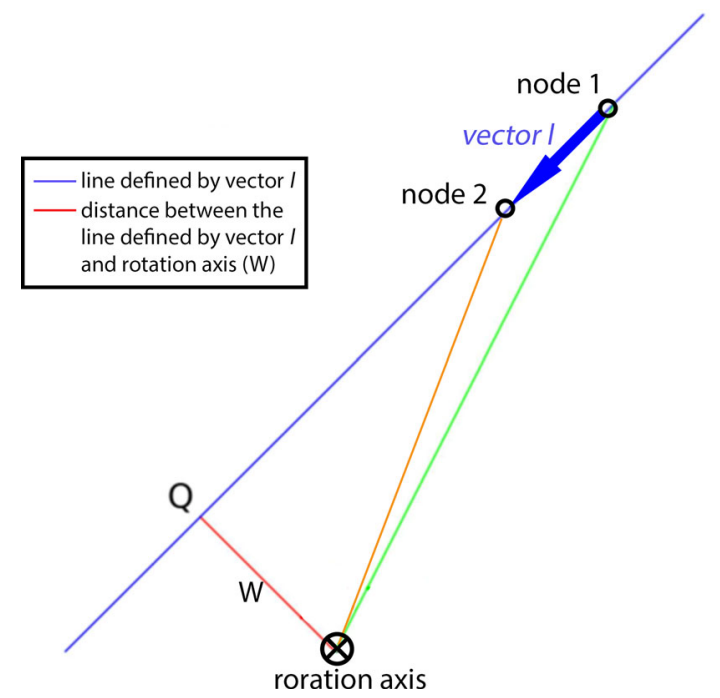

Fig. 9 Illustration of the quantity W, calculated for each pair of adjacent nodes, in every sprayed section

defined as $\mathrm{W}$. The quantity $\mathrm{W}$ is defined anew for each pair of adjacent nodes in a given sprayed section.

Additionally, $\omega$ is defined as the angular velocity of rotation of the sprayed part and $\psi$ the angle between vector $l$ and the projection of the vector of the spray plume to the plane of the analyzed sprayed section (Fig. 7); the traverse speed of the moving spray footprint $\left(V_{t}\right)$ can be expressed by Eq 1 . Angle $\psi$ is defined as the azimuth angle since it results from the projection of the spray plume vector to the reference plane.

$V_{t}=\omega\left(\sec \left(\frac{\pi}{2}-\psi\right)\right)^{2} W$

The illustration in Fig. 7, although not related with the examined rotor-like geometry, aims to highlight that, apart 
from the azimuth component (which changes during the part rotation), the impact angle is dependent on a zenith component which may result either from the complexity of the geometry or the inherent tilting of the spray plume (with respect to the reference plane).

In Fig. 10 and 11, the behavior of the azimuth angle and gun traverse speed of the 3rd sprayed section during one full rotation of the examined geometry is demonstrated, respectively. Since the azimuth angle is defined as the angle between vector $l$ and the projection of the spray plume on the reference plane (Fig. 7), it can take values from $0^{\circ}$ to $180^{\circ}$. The distinct, segmented linear behavior shown in Fig. 10 demonstrates the development of the azimuth angle along each of the six sides of the hexagonal sprayed section. In the area local to the corners of the hexagonal cross section (extreme values of azimuth angle in Fig. 10), some nodes appear to have significantly different values for the azimuth angle; the same can be observed in the behaviour of the calculated impact angle (Fig. 8). In both cases (Fig. 8 and 10), the calculated angles on the nodes that are located on the corners of the sprayed cross section appear to be closer to $90^{\circ}$, compared to the previous and next iteration. The notably different values of the azimuth and impact angles, which occurs on the corners of the sprayed geometry, can be explained by the behavior of the direction of vector $l$ (Fig. 7) in that region. Specifically, locally to the corners of the sprayed cross section, adjacent nodes which are located bilaterally to the corner point yield an $l$ vector notably different in direction, compared to the previous and next iteration. The calculated behaviour of the impact and azimuth angles on the corners captures reasonably what occurs experimentally when spraying over sharp corners, i.e., the impact angle is $90^{\circ}$ locally on the point of the corner. These results can be

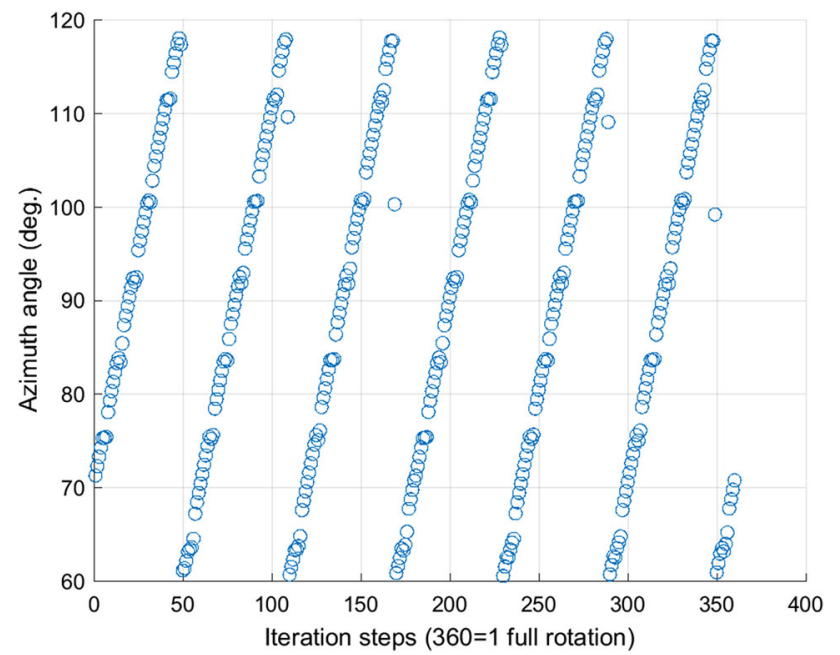

Fig. 10 Azimuth angle profile of the 3rd sprayed section during one full rotation of the part (external spray) reflected in the predictions which are made for the coating properties, which are discussed in "Prediction of Coating Properties on the Rotor-Like Model" section, as well as in the behaviour of the gun traverse speed (Fig. 11), since it depends on the azimuth angle (Eq 1).

\section{Interpolation of the Experimental Results}

After the calculation of the spray kinematic parameters (spray distance, impact angle and gun traverse speed) for each one of the nodes on the sprayed surface, the prediction space for each coating property needs to be constructed from the available experimental results (Table 1). As discussed in previous work (Ref 17, 18), the significant role of spray distance and spray angle in determining the particle impingement conditions does not allow for the isolated study of either one without considering the interplay between them. The same is not true for the effect of gun traverse speed since it does not influence the particle impingement conditions, rather it affects the coating via post-impingement mechanisms (Ref 18). In the light of the above, for each examined coating property, the effects of spray angle and spray distance are interpolated in a 3-D surface and the effect of gun traverse speed in a 2-D curve, yielding a 4-D prediction space (examined coating property $\times$ spray distance $\times$ spray angle $\times$ gun traverse speed) which expresses a coating property. In Fig. 12, the interpolation surfaces for spray distance and spray angle and interpolation graphs for the effect of gun traverse speed are presented, for microhardness (Fig. 12a and b), coating thickness (Fig. 12c and d), WC vol.\% (Fig. 12e and f) and specific wear rate (Fig. 12g and h). Detailed analysis and discussion of these coating properties take place in the previous (and future) work (Ref 17, 18).

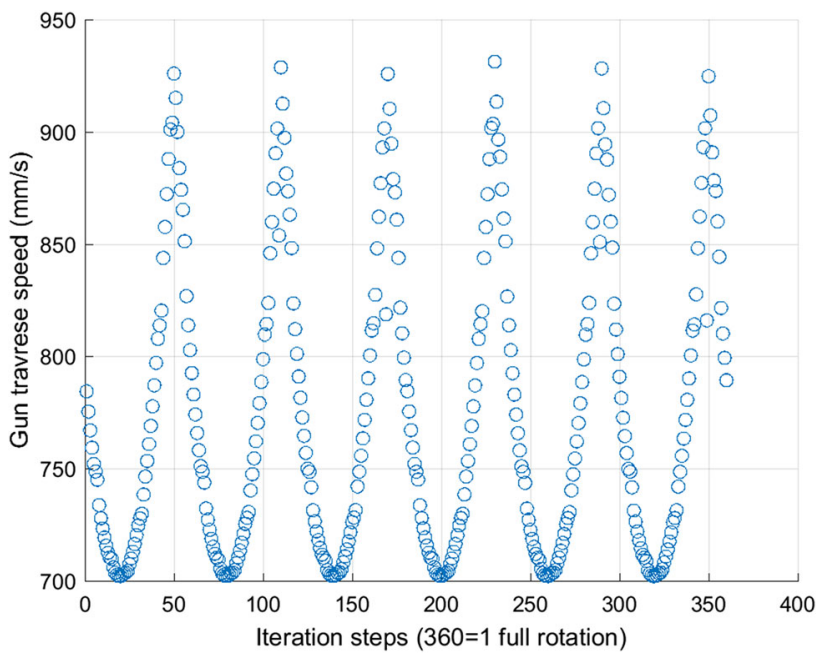

Fig. 11 Gun traverse speed profile of the 3rd sprayed section during one full rotation of the part (external spray) 


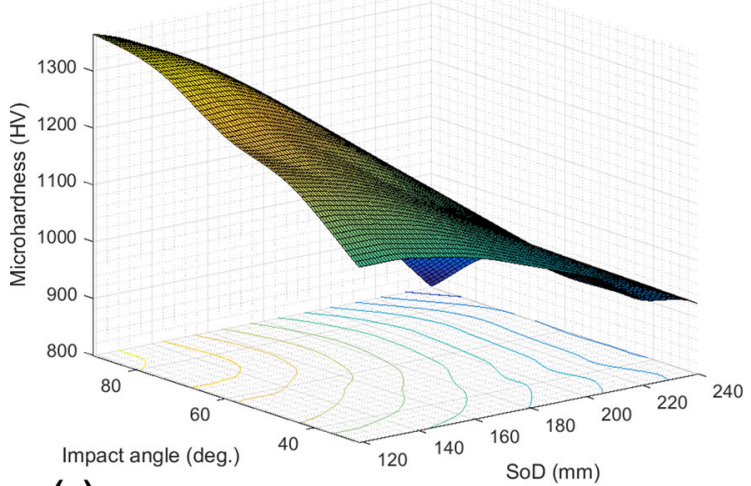

(a)

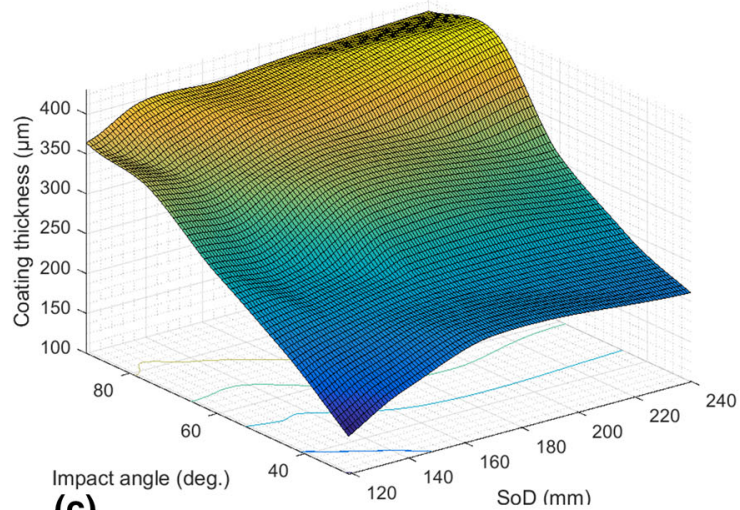

(c)

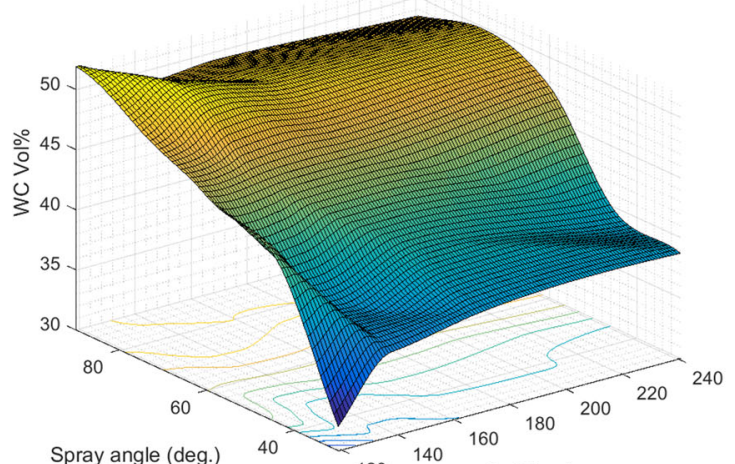

(e)

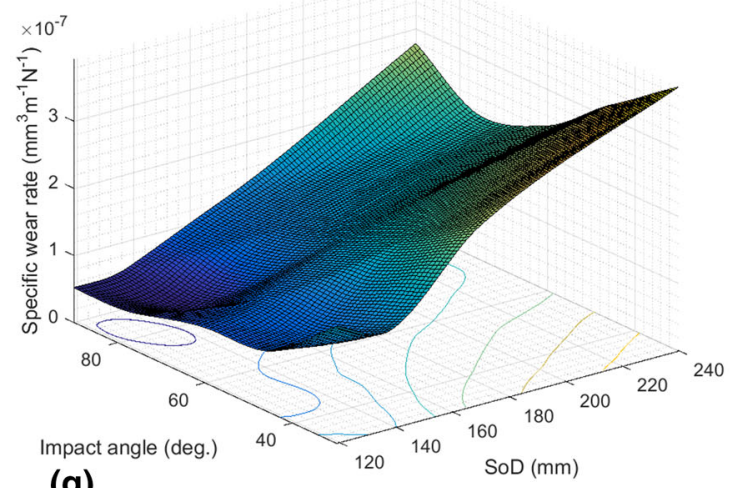

(g)

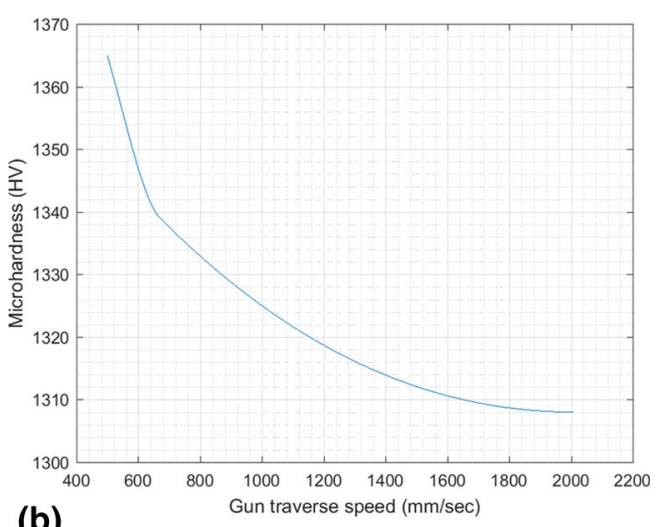

(b)
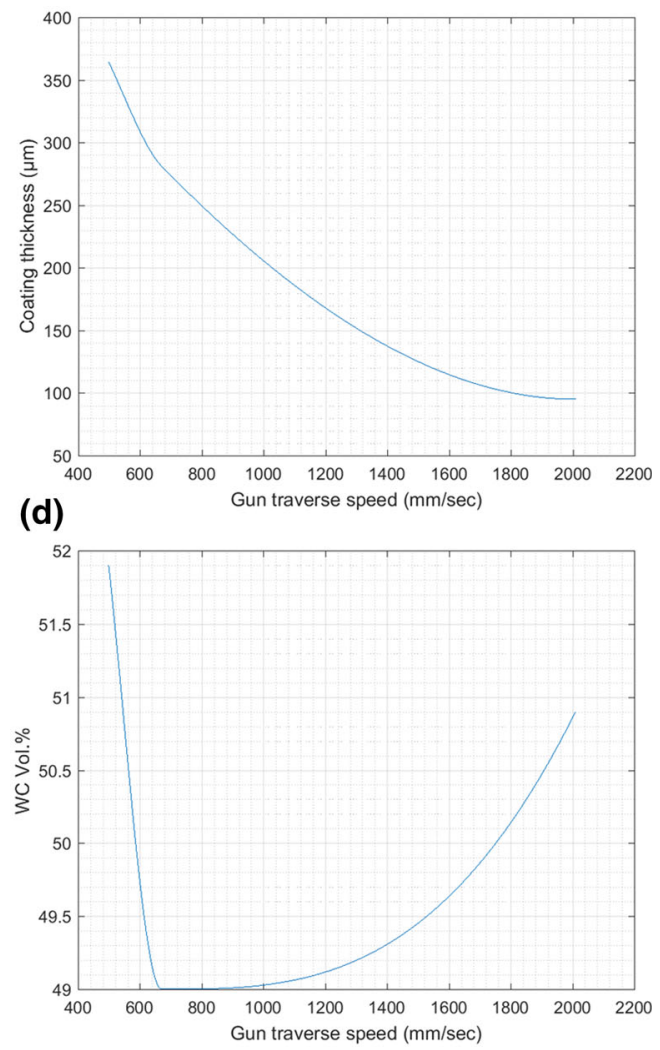

(f)

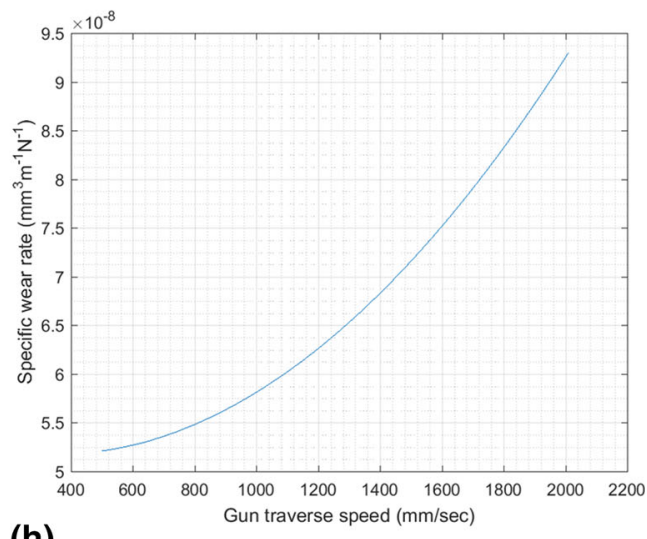

(h) 
4Fig. 12 Interpolation surfaces for the interplay of spray distance and spray angle and interpolation graphs for the effect of gun traverse speed for (a, b) microhardness, (c, d) coating thickness, (e, f) WC vol.\% and $(\mathrm{g}, \mathrm{h})$ specific wear rate. Data from (Ref 17, 18)

The interpolation method for the surfaces in Fig. 12 is "cubic" in MATLAB which is a triangulation-based cubic interpolation supporting 2-D interpolation only, and the interpolation method for the curves is "pchip," which is a shape-preserving piecewise cubic interpolation. Finally, the interpolated data are normalized to the maximum value to generalize the observations and express the influence of the kinematic parameters with respect to the optimum conditions.

\section{Prediction of Coating Properties}

The task of predicting the coating properties with respect to the sprayed geometry can be described as the mapping of the calculated kinematic parameters for each node to the prediction space, which is based on experimental results. In order to describe the mechanism of prediction of the coating properties with respect to the sprayed geometry, certain elements are introduced. Consider a matrix $N$ of size $i \times j$ where $i$ is the number of nodes that has been chosen to discretize each sprayed section $(i=360$ in this work) and $j$ is the number of sprayed sections needed to spray the examined geometry $(j=140$ in this work). Matrix $\mathrm{N}$ contains all the nodes that describe the sprayed surface. Each element $n_{i j}$ of $N$ contains the coordinates of the represented node, which are used for the kinematic calculations as discussed in "Kinematic Calculations" section. The function $d\left(n_{i j}\right)$ is defined, with $n_{i j}$ being an element of $N$, which returns the spray distance $(d)$ that corresponds to node $n_{i j}$, as described in "Kinematic Calculations" section. Respectively, the functions $a\left(n_{i j}\right)$ and $s\left(n_{i j}\right)$ are defined, which return the impact angle $(a)$ and gun traverse speed $(s)$ of the node $n_{i j}$, as described in "Kinematic Calculations" section. The functions $d\left(n_{i j}\right)$, $a\left(n_{i j}\right)$ and $s\left(n_{i j}\right)$ are continuous in $\mathbb{R}$, yet they should be within the range of the prediction space and accept discrete values of $n_{i j}$. The function $I^{c}\left(d\left(n_{i j}\right), a\left(n_{i j}\right)\right)$, continuous in $(0,1]$, which maps the values of spray distance and impact angle to the interpolated and normalized coating property “c $c$," for each node, for each sprayed section. Essentially, $I^{c}$ expresses the effect of the impact conditions to a coating property " $c$ " (which in turn is a function of spray distance and spray angle). The superscript " $c$ " indicates that $I^{c}$ concerns one specific coating property (i.e., microhardness). Similarly, the function $T^{c}\left(s\left(n_{i j}\right)\right)$ is defined, which is continuous in $(0,1]$ and returns the interpolated normalized effect of the gun traverse speed with regard to a coating property " $c$." The normalized prediction for each node $\left(P^{c}\left(n_{i j}\right)\right)$ of a coating property " $c$ " occurs as follows:

$P^{c}\left(n_{i j}\right)=I^{c}\left(d\left(n_{i j}\right), a\left(n_{i j}\right)\right) T^{c}\left(s\left(n_{i j}\right)\right)$

where $P^{c}\left(n_{i j}\right)$ is continuous in $(0,1]$ since it results from the product of $I^{c}$ and $T^{c}$. Therefore, by multiplying with a scaling factor $\beta$, being the highest value for each coating property as measured from the experimental run, the real prediction $\left(P_{r}^{c}\left(n_{i j}\right)\right)$ emerges:

$P_{r}^{c}\left(n_{i j}\right)=\beta P^{c}\left(n_{i j}\right)$

\section{Validation of the Method}

For the purpose of validating the proposed method, predictions for the case of a rotating plane surface around the spray gun were compared against experimental measurements from the same configuration, depicted in Fig. 2. The properties of coating thickness, microhardness and WC vol.\% are examined. In Fig. 13(a), the prediction curve and validation of coating thickness are demonstrated. The starting point (iteration 1) is considered to be at $90^{\circ}$ of spray angle, $120 \mathrm{~mm}$ of spray distance and at $500 \mathrm{~mm} / \mathrm{s}$ and the last point (iteration 45 ) at $45^{\circ}, 170 \mathrm{~mm}$ and at $1010 \mathrm{~mm} / \mathrm{s}$ (Fig. 13a). As the plane is rotated around the spray gun, the spray angle gets more oblique, the spray distance gets longer, and the gun traverse speed is increased (from the midpoint of the plane and towards its edge, Fig. 2). Each iteration point is equivalent to $1^{\circ}$ of rotation of the plane surface, since it is assumed that 360 iteration steps are needed for one full rotation of the part ("Initialization" section).

The simplified case of the rotating plane around the spray gun (Fig. 2) allows to plot the impact angle at the top $x$-axis in the graphs in Fig. 13, since there is a linear relationship between the iteration steps and the impact angle. Even though increasing the spray distance has a positive effect on the coating thickness (Fig. 12c), the negative effects of increasingly oblique spray angle and higher gun traverse speeds appear to dominate, resulting in a negative, nonlinear, trend as the spray plume approaches the edge of the rotating plane. The data points in Fig. 13 represent the experimental measurements taken from the rotating plane (Fig. 2) which serve as validation values for the respective predictions in Fig. 13. A good agreement is observed between the prediction and the experimental measurements $\left(R^{2}=0.87\right)$ for the coating thickness. Similarly, Fig. 13b and c shows the prediction and validation values for the WC vol.\% and microhardness yielding $R^{2}$ values of 0.87 and 0.95 , respectively. 


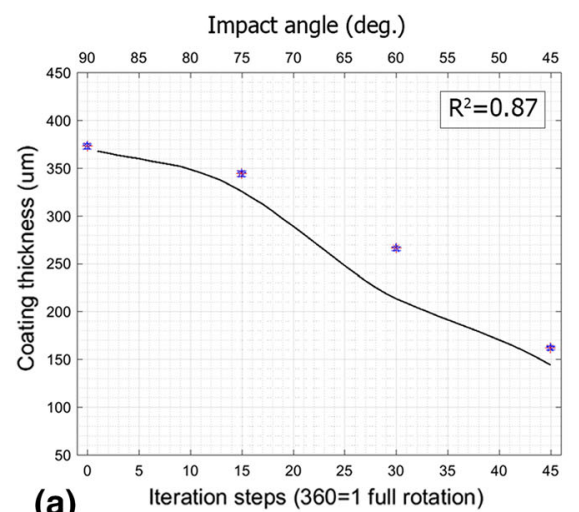

(a)

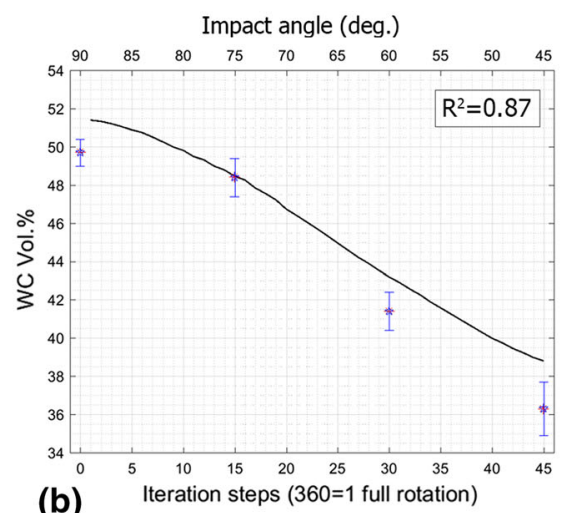

(b)

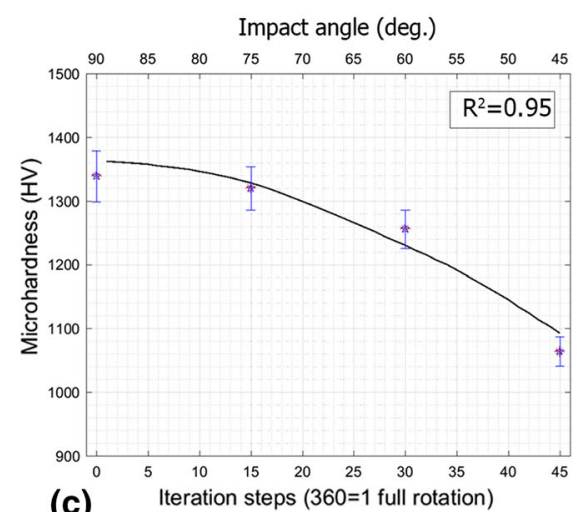

(c)

Fig. 13 Validation graphs for (a) coating thickness, (b) WC vol.\%, (c) microhardness and (d) specific wear rate. The curve represents the prediction for each property, and the data points are experimental measurements (Ref 17, 18)

\section{Prediction of Coating Properties on the Rotor-Like Model}

Following the prediction mechanism outlined in "Prediction of Coating Properties" section and the user input parameters in Table 2, Fig. 14 presents the predictions for coating thickness (Fig. 14a), WC vol.\% (Fig. 14b), microhardness (Fig. 14c) and specific wear rate (Fig. 14d) for the 3rd sprayed section (counting from the bottom of the geometry, Fig. 4). For the same sprayed section, the spray kinematic parameters are presented in Fig. 6, 8, 10 and 11 . Moreover, the scaling factor $\beta$ (Eq 3 ) was chosen considering the experimental results that were used for the construction of the prediction space ("Interpolation of the Experimental Results" section). That means that the prediction assumes the same number of spray cycles as the validation experiment (Ref 17). It can be seen that the behaviour of coating thickness (Fig. 14a) is mostly linear with six maxima and six minima, reflecting the hexagonal shape of the examined sprayed section. As the geometry is rotated in front of the spray gun, the coating is getting thinner as the spray footprint is approaching the corners of the hexagonal section due to the increasingly oblique impact angle and decreasing spray distance (Ref 17); thus, the minima in Fig. 14(a) correspond approximately with the corners of the hexagon. Yet, spikes in coating thickness values are observed locally on the sprayed corners (Fig. 14a), which is attributed to the impact angle becoming normal on the corner point, following the discussion in "Kinematic Calculations" section.

Regarding the rest of the predictions in Fig. 14 (WC vol.\%, microhardness and specific wear rate), a more intricate behavior is observed. In the WC vol.\% (Fig. 14b) and microhardness (Fig. 14c) predictions, a local inversion appears on the six maxima, which correspond with the midpoints of the sprayed hexagonal section. The same local inversion (though relatively augmented) occurs at the six minima of the specific wear rate prediction, which once again occurs at the midpoints of the analyzed hexagonal section.

The features of the predictions of microhardness, WC vol.\% and specific wear rate which are discussed above can be explained by the conflicting influence of spray angle and spray distance in regard to these coating properties. It was demonstrated in (Ref 17) that the maximum microhardness occurred at normal impact angle but was negatively affected by increasing spray distances $(>120 \mathrm{~mm})$. Similar dependencies on impact angle and spray distance were found to be true for the WC vol.\% (Ref 18) and the specific wear rate. Considering that as the spray footprint approaches the midpoint of the hexagonal section (3rd sprayed section), the impact angle approaches $90^{\circ}$ (Fig. 8), and the spray distance reaches its maximum value (Fig. 6), the two kinematic parameters compete against each other due to their conflicting influence on the examined coating properties. In that manner, the negative effect of increasing spray distance becomes more significant, after a certain threshold, which yields an inversion of the trend appropriately close to (1) the maxima for WC vol.\% (Fig. 14b) microhardness (Fig. 14c) and (2) minima for the specific wear rate (Fig. 14d). This nonlinear behaviour that is discussed above demonstrates why it is essential to consider the interplay of the spray kinematic parameters when studying the spray of complex geometries.

Aggregating the predictions of the all the consecutive sprayed sections that make up the analyzed geometry, Fig. 15 is constructed. Figure 15 presents the predictions for coating thickness (Fig. 14a), WC vol.\% (Fig. 14b), microhardness (Fig. 14c) and specific wear rate (Fig. 14d), for the external spray of the rotor-like geometry. Despite the lack of validation data for the specific wear rate prediction, the very good agreement of the microhardness 

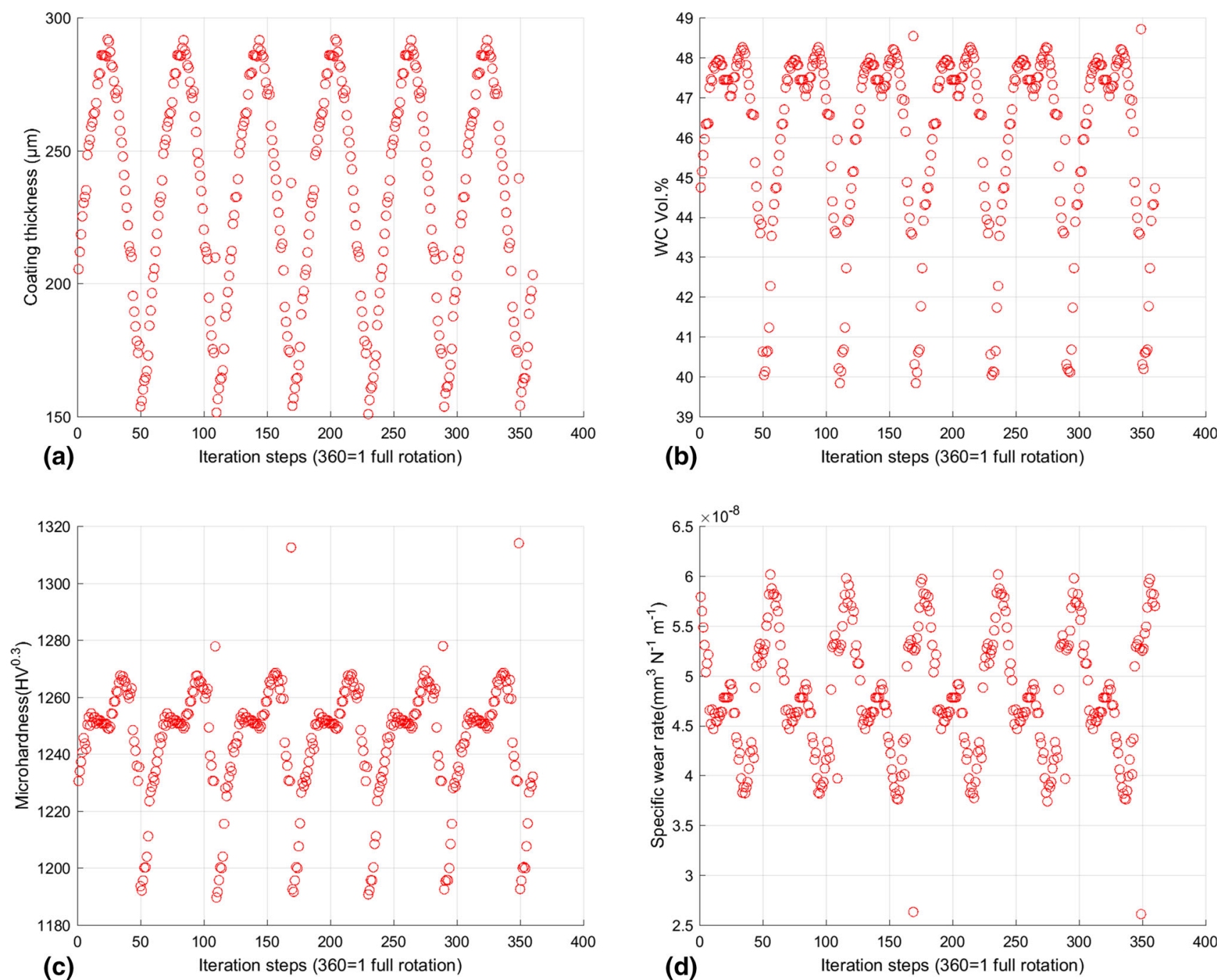

Fig. 14 Predictions of (a) coating thickness, (b) WC vol.\%, (c) microhardness and (d) specific wear rate, of the 3rd sprayed section from the bottom of the analyzed geometry

prediction with the experimental data (Fig. 13c) provides confidence for the validity of the specific wear rate prediction.

In Fig. 15, for each examined coating property, each node of the sprayed surface is color-coded with respect to the magnitude of the predicted value and plotted on the actual model in order to provide a visual representation of the predictions. It is clear that the worst values for each coating property occur in the proximity of the corners and edges of the geometry, owing to the associated oblique impact angles. This type of visualization is an intuitive way of displaying the predictions, and its value lies in highlighting the locations on the geometry that are expected to show critically sub-optimal coating properties in a direct manner.

\section{Conclusions}

In this work, the external spray of a rotor-like geometry is simulated via the geometrical analysis of a STL model and the correlation of the resulting kinematic parameter profile with appropriate experimental results. The experiments that provided the basis for the predictions and validation of the suggested method were of HVOF-sprayed WC-17Co. It is shown that coating thickness, microhardness, $\mathrm{WC}$ vol.\% can be predicted with relative accuracy, as indicated by the experimental validation. Additionally, the interplay between the spray kinematic parameters in respect of various coating properties can be captured by the prediction mechanism. In addition to the predictions of coating thickness, WC vol.\% and microhardness, which are 


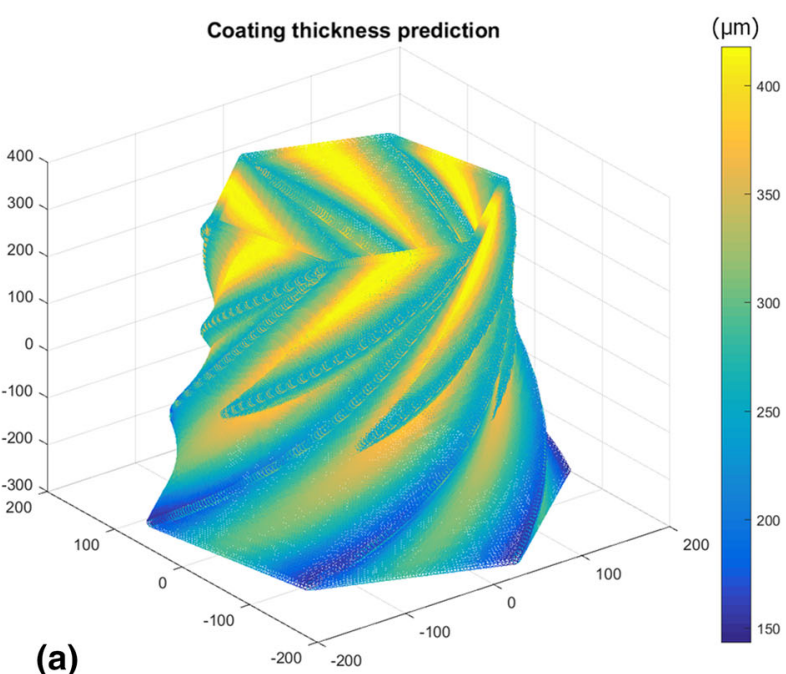

Microhardness prediction

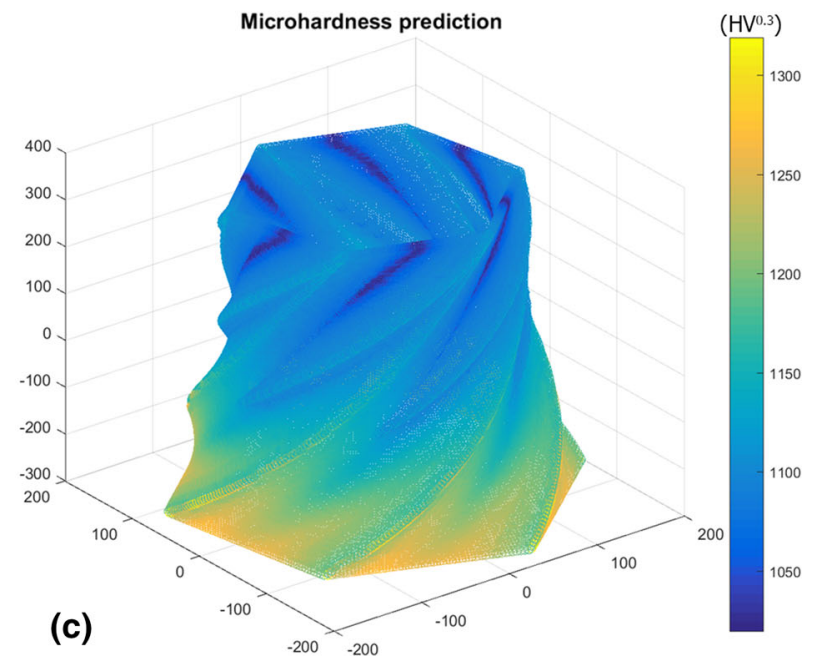

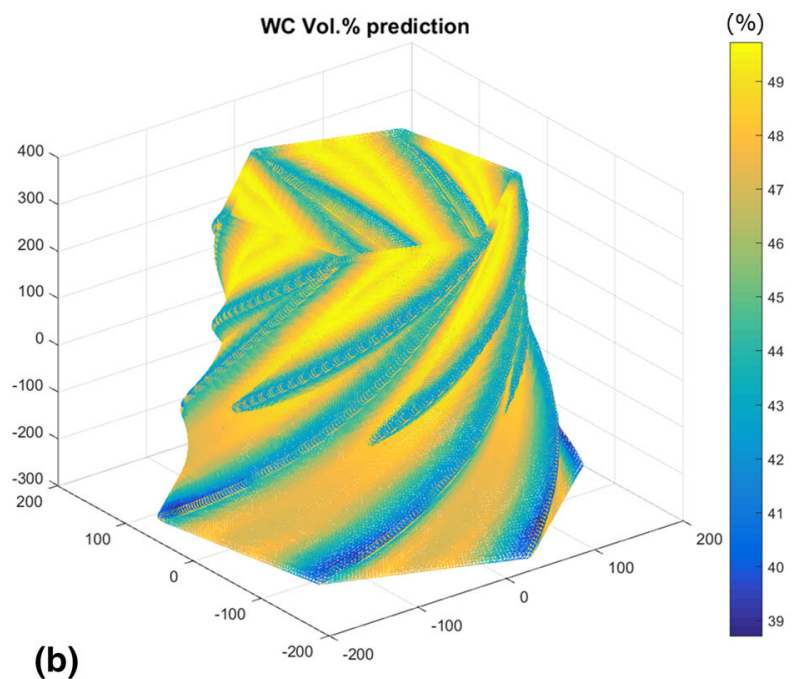

Specific wear rate prediction

$\left(\mathrm{mm}^{3} \mathrm{~N}^{-1} \mathrm{~m}^{-1}\right)$

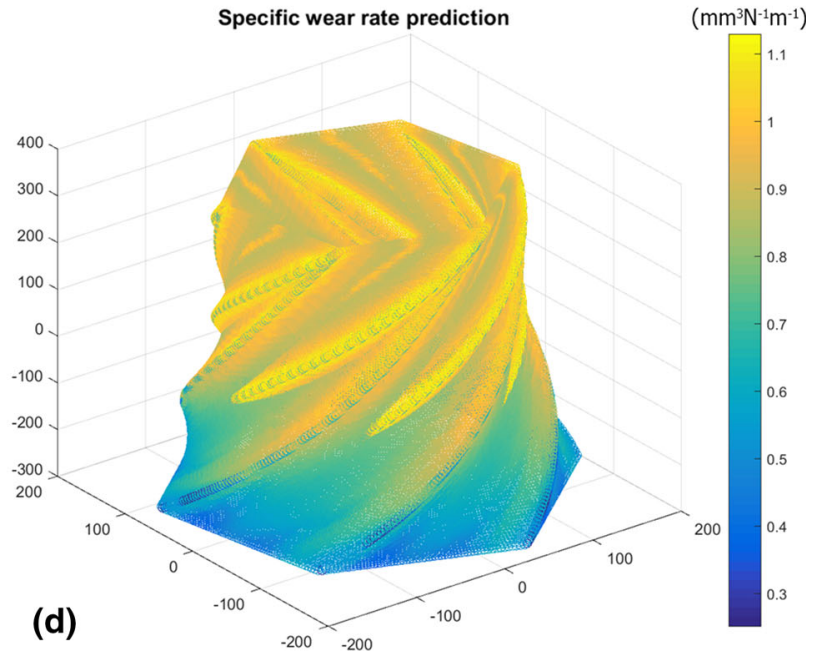

Fig. 15 Predictions of (a) coating thickness, (b) WC vol.\%, (c) microhardness and (d) specific wear rate, mapped on the analyzed model

validated experimentally, the specific wear rate is examined. The results have shown a progressive deterioration of all the examined coating properties as the spray kinematic parameters deviate from their optimal values, and more complex behaviours that result from the synergy of the spray kinematic parameters have been successfully captured. Finally, a visual representation of the predictions on the analyzed model enables the direct identification of the problematic locations on the geometry. The purpose of the modeling approach that is discussed herein is to accelerate the feasibility studies and decision-making with regard to novel applications of thermal spray coatings. The standardization of a set of initial experiments for the construction of the appropriate prediction space (examined coating property $\times$ spray distance $\times$ spray angle $\times$ gun traverse speed) using different materials and thermal spray processes will be able to generalize the predictive ability of the presented method.
Open Access This article is distributed under the terms of the Creative Commons Attribution 4.0 International License (http://crea tivecommons.org/licenses/by/4.0/), which permits unrestricted use, distribution, and reproduction in any medium, provided you give appropriate credit to the original author(s) and the source, provide a link to the Creative Commons license, and indicate if changes were made.

\section{References}

1. P.L. Fauchais, J.V.R. Heberlein, and M.I. Boulos, Thermal Spray Fundamentals from Powder to Part, Springer, New York, 2014, p 1401-1505

2. J.R. Davis, Handbook of Thermal Spray Technology, ASM International, Cleveland, 2004, p 47-52

3. D.A. Stewart, P.H. Shipway, and D.G. McCartney, Microstructural Evolution in Thermally Sprayed WC-Co Coatings: Comparison Between Nanocomposite and Conventional Starting Powders, Acta Mater., 2000, 48, p 1593-1604

4. C. Verdon, A. Karimi, and J.-L. Martin, A Study of High Velocity Oxy-Fuel Thermally Sprayed Tungsten Carbide Based 
Coatings. Part 1: Microstructures, Mater. Sci. Eng. A, 1998, 246, p 11-24

5. S. Eto, S. Kawano, S. Someya, H. Miyamoto, M. Sonohata, and M. Mawatari, First Clinical Experience with Thermal-Sprayed Silver Oxide-Containing Hydroxyapatite Coating Implant, $J$. Arthroplasty, 2016, 31, p 1498-1503

6. B.W. Allcock and P.A. Lavin, Novel Composite Coating Technology in Primary and Conversion Industry Applications, Surf. Coat. Technol., 2003, 163-164, p 62-66

7. A. Sanz, Tribological Behavior of Coatings for Continuous Casting of Steel, Surf. Coat. Technol., 2001, 146-147, p 55-64

8. J.A. Picas, M. Punset, M. Teresa Baile, E. Martín, and A. Forn, Tribological Evaluation of HVOF Thermal-Spray Coatings as a Hard Chrome Replacement, Surf. Interface Anal., 2011, 43, p 1346-1353

9. R. Gadow, A. Candel, and M. Floristán, Optimized Robot Trajectory Generation for Thermal Spraying Operations and High Quality Coatings on Free-Form Surfaces, Surf. Coat. Technol., 2010, 205, p 1074-1079

10. W. Tillmann, E. Vogli, and B. Krebs, Influence of the Spray Angle on the Characteristics of Atmospheric Plasma Sprayed Hard Material Based Coatings, J. Therm. Spray Technol., 2008, 17, p 948-955

11. W. Tillmann and B. Krebs, Influence of Handling Parameters on Coating Characteristics in Order to Produce Near-Net-Shape Wear Resistant Coatings, J. Therm. Spray Technol., 2012, 21, p 644-650

12. U. Selvadurai, P. Hollingsworth, I. Baumann, B. Hussong, W. Tillmann, S. Rausch, and D. Biermann, Influence of the Handling
Parameters on Residual Stresses of HVOF-Sprayed WC-12Co Coatings, Surf. Coat. Technol., 2015, 268, p 30-35

13. W. Tillmann, I. Baumann, P. Hollingsworth, and I.-A. Laemmerhirt, Influence of the Spray Angle on the Properties of HVOF sprayed WC-Co Coatings Using $(-10+2 \mu \mathrm{m})$ fine Powders, $J$. Therm. Spray Technol., 2013, 22, p 272-279

14. G. Montavon, S. Sampath, C.C. Berndt, H. Herman, and C. Coddet, Effects of the Spray Angle on Splat Morphology During Thermal Spraying, Surf. Coat. Technol., 1997, 91, p 107-115

15. F. Trifa, G. Montavon, and C. Coddet, On the Relationships Between the Geometric Processing Parameters of APS and the $\mathrm{Al}_{2} \mathrm{O}_{3}-\mathrm{TiO}_{2}$ Deposit Shapes, Surf. Coat. Technol., 2005, 195, p 54-69

16. M. Gui, R. Eybel, B. Asselin, S. Radhakrishnan, and J. Cerps, Influence of Processing Parameters on Residual Stress of High Velocity Oxy-Fuel Thermally Sprayed WC-Co-Cr Coating, $J$. Mater. Eng. Perform., 2012, 21, p 2090-2098

17. V. Katranidis, S. Gu, B. Allcock, and S. Kamnis, Experimental Study of High Velocity Oxy-Fuel Sprayed WC-17Co Coatings Applied on Complex Geometries. Part A: Influence of Kinematic Spray Parameters on Thickness, Porosity, Residual Stresses and Microhardness, Surf. Coat. Technol., 2017, 311, p 206-215

18. V. Katranidis, S. Gu, T.R. Reina, E. Alpay, B. Allcock, and S. Kamnis, Experimental Study of High Velocity Oxy-Fuel Sprayed WC-17Co Coatings Applied on Complex Geometries. Part B: Influence of Kinematic Spray Parameters on Microstructure, Phase Composition and Decarburization of the Coatings, Surf. Coat. Technol., 2017, 328, p 499-512

19. D. Legland, geom3d, MATLAB 9.1 (R2016b), 2017. 